\title{
How To Achieve Effective Teamwork: The View of Mental Health Professionals
}

\author{
Fahriye Oflaz' (1), Gülsüm Ançel ${ }^{2}$, Filiz Arslan³ ${ }^{3}$ (1) \\ 'Koç University School of Nursing, İstanbul, Turkey \\ ${ }^{2}$ Department of Nursing, Ankara University School of Health Sciences, Ankara, Turkey \\ ${ }^{3}$ Department of Nursing, Yeditepe University School of Health Sciences, İstanbul, Turkey \\ ORCID IDs of the authors: F.O. 0000-0002-3878-028X; G.A. 0000-0002-6756-5132; F.A. 0000-0002-7335-0218.
}

Cite this article as: Oflaz F, Ançel G, Arslan F. How To Achieve Effective Teamwork: The View of Mental Health Professionals. Cyprus J Med Sci 20I9; 4(3): 235-4I.

\section{BACKGROUND/AIMS}

The nature of multidisciplinary teamwork in mental health care is diverse and complex. However, effective teamwork is still one of the main means to achieve the expected outcomes in the mental health field. Since teamwork requires face-to-face relationships, it is important to sharing meanings to provide effective care. This study aimed to explore how mental health professionals describe teamwork and to reveal difficulties they face and provide solutions from their own professional standpoint.

\section{MATERIALS and METHODS}

This exploratory qualitative study was conducted at psychiatry departments of three university hospitals. The critical case technique was used as a purposive sampling method. Semi-structured interviews were conducted with 15 health professionals, including psychiatrists, nurses, social workers, and psychologists who worked at psychiatric inpatient units. Thematic analysis was applied in data evaluation.

\section{RESULTS}

The themes were categorized under three headings: concepts, barriers, and suggestions. Sharing the tasks and mutual acceptance of roles were the factors most stated as necessary for achieving effective teamwork in the inpatient unit. Avoidance to take responsibility, strict hierarchy, underestimating the roles of other team members, personalization of problems, an inadequate number and qualification of staff, and a rapid staff turnover were remarkable obstacles. Participants stressed the importance of a work environment that focuses on the needs of patients and open communication.

\section{CONCLUSION}

In this study, we tried to explain the subjective dimension of the possible reasons of the failure to achieve teamwork in mental health care provision. The findings suggest that mental health professionals used similar concepts when explaining teamwork. However, they had different ideas about how to shape and conduct teamwork.

Keywords: Mental health care, mental health professionals, qualitative research, teamwork

\section{INTRODUCTION}

In health care provision, needs of patients are diverse and change over time, while the roles of health care professionals are often flexible, and leadership changes depending on the required expertise. That is why achieving effective multidisciplinary teamwork is a sine qua non in providing high-quality services, research, and education in health care (I-4). Many authors have addressed the benefits of effective teamwork, such as a reduced hospitalization rate and costs, an improved service provision, enhanced patient satisfaction, and staff motivation and innovation. However, studies show that it is difficult to achieve effective teamwork. Thus, a significant percentage of medical errors has been attributed to communication breakdowns caused by lack of effective teamwork (3-8).

Multidisciplinary work, facing obstacles in every field of health care, is more difficult in mental health care services due to a high degree of uncertainty and interdependence. Since the role is more certain among the professionals in other medical areas, teamwork usually does not create as much of a threat as it does in mental health teams. However, role boundaries still represent an ambiguous issue for mental health care and need to be addressed so that we can reach optimal outcomes $(3,5-7,9)$. 
Although each mental health professional introduces himself or herself as nurses, doctors, or psychologists, they are all working with individuals, families, and groups for similar goals, such as increasing the self-confidence of the patient, improving problem-solving and life skills, including social interactions. The overlap of roles in these conditions is natural, and it is difficult to determine the role boundaries. That is why achieving effective teamwork is very challenging. In such cases, roles should be integrated for the patients' benefit rather than struggling to separate them $(1,6,7,10,11)$.

A constant discipline-specific language in a multidisciplinary environment can create a silo effect in the health care services (12). For this reason, to achieve an effective teamwork, shared mental models, and open communication are crucial. That is, common understanding about teamwork can facilitate and increase communication in clinical settings, especially in mental health area (I3). Teamwork needs a set of interrelated behaviors and actions that occur among workers while performing a task. That is why team members should share discuss information about the patient by keeping in mind that the roles under the surface are transitive. However, there are differences in perceived roles in the team, and these differences are due to different training and professional socialization of the members $(14,15)$.

Difficulties in establishing and maintaining effective teamwork usually have been attributed to the lack of communication, lack of collaboration and shared decision making, and differences in professional education $(7,8,16-18)$. If we think of health care as of a large puzzle, each intradisciplinary team is like one special piece of this puzzle. The uncertainity about the team and teamwork definitions determines the nature of communication, creating ambiguity and role conflicts and causes non-conformity in the parts of the puzzle. Differences in definitions of the teamwork change the way of the communication, regardless of how skillful the person is or how qualified and/or expert (8, 16, 17). Thus, shared meanings, as noted in Lo (19), can help professionals to visualize the whole puzzle.

In this study, we aim to show the perception of mental health professionals using their own language. The purpose of the study is to describe effective teamwork from the perspective of mental health professionals and to explore concepts from their own point of view. We examined which concepts the mental health care team members use to describe teamwork, and how they define problematic teamwork areas.

\section{MATERIALS and METHODS}

\section{Participants and Setting}

This exploratory study was conducted at inpatient psychiatry units of three university hospitals in Ankara, Turkey. The critical case technique as a purposive sampling method was used in the study. This sampling method is a widely used method in qualitative research, where the sample consists of individuals being selected because they are especially knowledgeable about or experienced with a phenomenon of interest. A referral sampling was used to reach the participants. These health professionals were psychiatrists, nurses, social workers, and psychologists. The inclusion criteria were I year of experience working in an inpatient psychiatric unit.
The working style was very similar among these three hospitals. Each inpatient unit had a 35-45-bed capacity. Each discipline had specific responsibilities. For instance, psychiatrists were the team members who decided to admit and discharge patients. Psychologists were usually administering the tests to help the diagnosis, and the nurses were responsible for all functions of inpatient care. Social workers were doing family interviews. However, the roles of each discipline were complementary related to the treatment and recovery process.

Participation in the study was voluntary, and all participants gave verbal consent. The first two authors of this study interviewed the respondents. After being given information about the study and accepting to participate, the interviews were initiated and tape-recorded.

Twenty-four health professionals were invited to participate in the study, and 15 volunteered to participate ( 6 nurses, 2 social workers, 3 psychologists, and 4 psychiatrists). Of participants, 10 were women and 5 were men. The number of professional experience years ranged from I to 30 years. The professionals who did not want to participate in the study usually said they had no time for the interview. However, all of them helped the researchers to approach another person who would have time for the interview. The participants mostly started to talk broadly, including localized daily problems in the work environment, and interviews were conducted until the theme saturation was achieved.

\section{Data Collection}

Interviews were conducted in the participant's workplace in a private room individually in Turkish. Participants did not meet the researchers personally before the study. Two two authors of this study who were pschiatric nursing faculty, interviewed the respondents. They were experienced in interviewing techniques.

There was an interview guide consisting of three open-ended questions for interviews. In order not to direct the participants' answers to a particular issue, the questions were quite general. The questions were

- Could you explain your definition of a team or the idea of teamwork?

- How would you describe effective teamwork?

- What should be done to improve teamwork?

In addition, interviewers also asked if they had any formal/specific education or training about teamwork. During the interview, probes were used when needed. The interviews ranged from 30 to 60 minutes. All interviews were audio recorded and transcribed verbatim.

\section{Data Evaluation}

Authors used thematic analysis for data evaluation. Thematic analysis had the following six steps: familiarization with the data, generating initial codes, searching for themes, reviewing themes, defining/naming themes, and producing the report. "Coding" refers to the creation of categories in relation to data; the grouping together with the different instances of the datum under an umbrella term that can enable them to be regarded 
as "of the same type" (18). The constant comparison approach was applied, and emerging themes were refined and compared with the data. In the formulation process of the themes, authors re-evaluated the statements independently to strengthen the validity of the themes.

Since the study did not involve any interventions or include a vulnerable population, and since it was based on the thoughts of professionals, a formal ethical approval was not required for this study. In accordance with the Declaration of Helsinki, written and verbal information about the study and the nature of the study was provided to the participants, and their verbal consent was obtained before the interviews. The participants were informed verbally about the purpose, privacy, and voluntary basis of the research and that they were free to terminate the interviews whenever they wanted. Participants who gave informed consent were interviewed.

\section{RESULTS}

Under the three main categories, 6 subthemes emerged (Table I). The categories were the following: "concepts embodied in teamwork definition," "barriers to teamwork," and "suggestions for effective teamwork." Categories and theme-related quotes of the participants were given in the following. Each number after the statement refers to one participant.

None of the participants had any formal/specific education or training about teamwork. Their statements were usually based on their own work experiences. They stated that they could talk about their personal inferences only that is, about how they formed their teamwork view and definitions in their course of working years.

\section{Category I. The Concepts Embodied in Teamwork Definition}

Participants, defining teamwork, mostly focused on leadership. They also emphasized sharing tasks by addressing patient needs as central part. In addition, admitting the roles of other team members during the teamwork are important components, as well as open communication.

Team members emphasized the importance of good quality leadership. A team leader was mentioned as the person responsible for maintaining a motivating environment. Participants noted that acknowledging roles of other team members was as crucial as professional competence. However, they stated that roles sometimes might change according to the specific needs of patients and professional competencies of the team members. In addition, to be able to achieve teamwork, focusing on patients' needs was an important component. Examples of statements were as follows:

...The personality traits of the manager are very important. However, being a leader takes time, and it is very important to be a role model (R9).

...The team leader should understand that every person has different motivation resources and should take some preventive

TABLE I. Categories and subthemes

\begin{tabular}{|c|c|}
\hline Categories & Themes \\
\hline \multirow[t]{4}{*}{ Category I: The concepts embodied in teamwork definition } & The concepts \\
\hline & Good quality leadership \\
\hline & Professional competence \\
\hline & Open communication \\
\hline \multirow[t]{5}{*}{ Category 2: Barriers to teamwork } & Individual-related barriers \\
\hline & Avoiding responsibility/pass the buck \\
\hline & Devaluing and trivializing others' contributions and roles \\
\hline & Personalization of the problems \\
\hline & Staffing problems; rapid changes in staff, lack of staff \\
\hline \multirow[t]{7}{*}{ Category 3: Suggestions for effective teamwork } & Competent leadership \\
\hline & Supporting the leaders to improve their leadership traits \\
\hline & Creating an effective communication atmosphere \\
\hline & Structured team meetings to give everyone the right to speak \\
\hline & Establishing an information flow to improve collaboration \\
\hline & Supporting team members financially and for personal development \\
\hline & $\begin{array}{l}\text { Improving personal characteristics (respectfulness; being tolerant and unprejudiced, } \\
\text { flexibility; ability to listen, openness toward criticism) }\end{array}$ \\
\hline
\end{tabular}


measures to motivate each person. They also create a dynamism and cohesion in the team (RI2).

... Of course, every professional should know his or her own job very well. However, they also should know about the other team members' jobs or try to know about them and must appreciate what others do... (RIO).

...Teamwork means sharing the tasks... Whatever the focus of us, everyone in the team should do their best; they should do whatever they know best. I mean the tasks should be shared... (R6).

...For me, it is an integration of every task, and work has been done focusing on patient's needs... (R2).

... This is a $24 / 7$ continuous service. For this reason, every person in the team should focus on the patients and their needs. Focus must be on the patient... (RI).

The other valued concept was communication. Communication was considered crucial to provide effective teamwork.

...While doing your job, you should be aware of working in a team and communicate with each member openly. Otherwise, you cannot provide collaboration... (R3).

... For teamwork, being unprejudiced is important. You can have opposite thoughts or opinions, but respect is crucial (R8).

In summary, leadership was a fundamental factor affecting communication and role performance. Role clarity and professional qualifications are important, but patient needs should be prioritized.

\section{Category 2. Barriers to Teamwork}

Under this category, two main themes emerged as "individual-related barriers" and "organization-related barriers." Individual-related barriers included negative attitudes including avoiding responsibilities, devaluing and/or trivializing contributions and roles of other team members, personalization of problems and working alone, and/or not being able to collaborate. According to participants, if a team member is not a good collaborator and is working alone, or not taking responsibility when needed, it is obvious that conflicts among team members and needs of patients will be unmet.

...If the person says that "This is not my task," "I do not want to do that," or "I'm tired, someone else must do it" etc., it blocks the communication channels and prevents teamwork. People who ask, "Is this our job?" and who are not motivated to work interfere with the motivation of team (RIO).

... To progress in the treatment plan, all the professions should contribute to the work. It is for the benefit of the patients. If there is collaboration in the team, you can see the outcomes fast... (RI0).

...Some of my colleagues say to me, "these are physicians' tasks; we should not do that. If we do it, it becomes as our task in time"... these statements make me confused. There is a task, but nobody takes the responsibility, but in fact, this is for patient, it is not for someone else (RI).
... Here, everybody is aware of his or her own limits. Sometimes inexperienced new people may break the role limits. If you see any conflict in the team, this is mostly the main reason (RII).

... We need not to personalize everything around us. Focus must be on the patient... (RI).

Participants addressed that each team member must believe in the effectiveness of teamwork. "Avoiding sharing and taking responsibilities when flexibility was needed," and "the personalization of problems" were addressed as barriers by team members.

One of the "organization-related barriers" was strict hierarchy, and the other one was staffing problems. Although participants talked about the need of hierarchy in a positive way, they also emphasized strict and vertical hierarchy as a barrier for effective teamwork.

...Hierarchy is not a negative thing in fact, but if it causes pressure and fear, it blocks productive working (RI4).

... Naturally, the boss is the chief of department and after him/ her, the chief of ward and other doctors come. Hierarchy goes like that unfortunately... Actually, I believe that it must be a circle. It must be a horizontal management (RI3).

As to staffing problems, there were two main issues. One is staff turnover frequency and the second is lack of staff:

... If there is no continuity among the staff, you cannot mention about the teamwork. People who know each other can produce synergy. A certain time for adaptation is needed. If you are in a I0-person team, and 6-7 persons leave soon and new persons start, you cannot keep going the same way (RI4).

... There was a steady nursing staff in the unit previously, but lately it has changed. It is a vicious circle, one person comes, and you teach her/him and then s/he goes, and another one comes. This causes negative effects on the continuity of care (RI5).

... There are only two psychologists, and one of them is pregnant and will leave the job soon. Only one person will work then. The lack of nurses is a routine problem too. So, it is impossible doing something other than the routines (R9).

\section{Category 3. Suggestions for Effective Teamwork}

Participants addressed the need for effective and competent leadership to motivate team members to maintain teamwork. They suggested that leaders needed to be supported to improve their leadership traits. Some quotes emphasizing the importance of capability of the team leader were as follows:

... The attitude of the leader is very important. If the chief of department values teamwork and gives the opportunity to apply, it is very easy to reach the people (R4).

.. If the leader is not competent and does not recognize teamwork, it is impossible to work as a team. In addition, the justice is very important in the team, and the leader should provide this (RII). 
...The team leader should understand that every person has different motivational resources and should take some preventive measures to make each person motivate. They also should create a dynamism and cohesion in the team (RI2).

In addition, a democratical atmosphere meant giving everyone the right to speak, for participants. That is why they suggested structured team meetings to facilitate talking to each other and sharing information. Also, a flow of information within the team was a guarantee of improved collaboration.

... Arranging some programs to know each other is important. If we want effective teamwork, we should talk to each other. I must be aware of the other team members and the impact of their work on my tasks and plans... (R8).

...Hierarchy must be loosened. Of course, everybody has different experiences and thoughts, and you can learn from others. Team members should feel free to talk within the team (RI4).

...t must be an environment to have the right to talk equally and freely. I should be able to talk without hesitation... (R9).

...Everybody should feel that they are the part of a team. To be able to provide this and make them feel valuable, team meetings and sharing the information is very important (R3).

Supporting team members financially and giving them opportunities for personal development emerged as another important component to improve teamwork. Participants emphasized that improving personal characteristics, such as respectfulness, tolerance and not showing bias or prejudice, flexibility, active listening, and openness toward criticism may increase collaboration.

.. When something has been criticized, you must listen first without any reaction. You should care about what was said. Reacting before listening causes conflicts (R8).

... Personality is very important. Being egocentric and rebellious or dominant during the work causes conflicts (RIO).

Team members mentioned financial problems as an important factor contributing to the lack of staff and frequent staff turnover. According to participants, if the payments or salaries become more satisfactory, this would help keep team members together in the same work setting.

... Financial problems affect the teamwork negatively. It causes both a rapid personnel change and dissatisfaction with the work. Special compensations, which are added to salaries for the psychiatry personnel, could solve these problems (R8).

\section{DISCUSSION}

In this study, mental health team members explained what concepts are important for teamwork from their perspective. Task sharing focusing on patient needs, and identification and mutual acceptance of roles, as the most important features of teamwork, were emphasized topics in our study. In addition, participants emphasized open communication, and democratic and active leadership features.
In the related literature, knowing how team members perceive their own and others' roles are addressed as a very important component in understanding the collaboration necessary for multidisciplinary teamwork. Another important issue is acknowledgment of other members' expertise and roles. Members must be respectful with the responsibilities and boundaries of each discipline, and the atmosphere should allow each discipline to present their own specific skills, understandings, and roles $(20,21)$.

In this study, barriers to teamwork were factors such as avoiding responsibility, difficulty in getting together, strict hierarchy, devaluing the different roles of team members, personalization of problems, inadequate number and quality of staff, and rapid staff turnover have been stated. Especially, the lack of information and motivation, inexperience, frequent change of employees, lack of quality of staff and some unsolved administrative problems were mentioned as well. On the other hand, there was an acceptance about the possibility of having conflicts within the team as a natural phenomenon.

Like our participants, Kelly (22) states that conflict is a natural phenomenon in which there has been disagreement between individuals who perceive a threat to their needs, interests, and/ or concerns. Conflicts can emerge due to relationships and to tasks. Heimer (23) suggested that conflict resolution can be an opportunity for growth and change and a positive outcome. Shaw et al. (24) reported that moderate task conflict and low relationship conflict can lead to good performance. According to participants of this study, if each team member prioritized and focused on patients' needs while they perform their own role, conflicts would be easily solved. This finding coincides with the view that putting the patient at the center reduces tension among the team members (25).

Conflicts usually occur due to interprofessional misunderstandings, different conceptual approaches, different lines of accountability, and imbalances in power, lack of leadership, and lack of communication. Other additional reasons contributing the conflicts are not knowing the professional boundaries, ineffective assertion, psychological unsafety, lack of situational awareness, and the personality traits of members and the overlaps and conflicts in roles. Therefore, improving a number of qualifications such as working together, taking responsibility, coping with anxiety, controlling their emotions, and being trustworthy is very important in maintaining successful teamwork (26-30).

The other main concept in this study was hierarchy. Almost all the professionals mentioned hierarchy. Hierarchy is a structure that exists in almost all health teams, and physicians are usually supposed to manage the team (14). The participants accepted the hierarchical structure, and it was seen that management of the treatment program by the physician was acceptable. On the other hand, it was emphasized that there should be no rigid hierarchy and authoritarian attitudes of the team leaders. Singh (28) states that such attitudes lead to hostility and aggression, as well as obedience. Therefore, in a rigid hierarchical structure, it can be difficult to develop motivation, spiritual pleasure, and creativity. Some authors suggest that hierarchy reduces success in achieving group cohesion, and in particular, it causes inef- 
fective communication between nurses and physicians (31, 32). However, in a hierarchical structure, democratic communication and balanced power relations in the team and teamwork can be adversely affected. In fact, the "bottom-line hierarchy" in which there has been a decision maker is proposed, as a well the functioning structure to enable each member to understand his or her responsibilities, resolve conflicts, and make tough decisions. Hence, although the team-as-a-whole concensual and democratic form of decision making is a good mode of operation, a bottom-line hierarchy with a designated decision maker is vital to ensure that individual professional responsibility is understood, the conflicts are resolved, and difficult decisions are made (28).

As solutions, participants made suggestions that would make communication more clear among the team members to provide effective teamwork. Written or oral communication and team meetings that provide sharing of the information in a democratic milieu were suggested as the tools to solve problems most easily. In this study, regular team meetings, active listening, and non-critical and empathic communication were emphasized to ensure functional communication. In the literature, for the team to be functional, it is stated that it is necessary to create new and professional interaction patterns, to accept changes in authority and status, and to develop conflict resolution and decision making skills $(1,7,10,33)$. To achieve that training programs should be planned in such a way that health professionals can learn from each other and with each other. The structured communication methods such as debriefing, assertive language, critical language, common language, closed communication loops, active listening, and callouts can be used in those programs. In addition, training on assertiveness and mutual trust has been suggested to reduce the negative effect of hierarchy as well $(19,21,31)$.

Qualitative description is especially suitable for obtaining straight and largely unvarnished answers to questions of special. The reasons for particular types of behavior can only be understood when it is observed, and people are asked about it $(33,34)$. Using in-depth interviews in this study provided the opportunity to reveal novel information on what is defined and what is problematic for teamwork to mental health professionals. Findings revealed that definitions have some conceptual differences, even if they are named the same way. In this paper, we suggested a descriptive analytic model in viewing the possible reasons of the teamwork failure. Often when teamwork fails, we feel lost when assessing the reasons of its failure. As Onyett and Campling (10) stated, as we become more sophisticated about the nature of teamwork, it is important that we continue to aspire to this rigor; otherwise we will not be in a position to assess accurately whether we are achieving effective teamwork or not.

A limitation to this study is that the findings may reflect the perspectives of mental health professionals who work in the inpatient hospital setting; mental health professionals who work with outpatients or in the community setting may have different perceptions of teamwork.

In conclusion, we saw that mental health team members had developed their own teamwork perspective and personal style according to work conditions at where and when they had started to work. This finding was consistent with other studies and supported that due to "little formal training on teamwork in undergraduate or postgraduate health professional education, teamwork skills are largely learned 'on-the-job'" (35). Our suggestion for achieving effective teamwork is that it should be taught during undergraduate education and be continuously developed later in working life. In related publications, it is stated that the training programs increase the effectiveness of the team, and interdisciplinary training about communication and teamwork is useful for improving safety culture in health care settings $(19,21,23)$.

\section{Implication for Practice}

Maintaining teamwork effectively in the mental health field is crucial to achieve positive outcomes. In this era, technology is changing the health care setting and the provision of health care, but we think that even in these advanced technological and digital environments, teamwork directly affects the course of patients' recovery process. Understanding subjective meanings and communalizing them is useful in preventing possible failures.

Thus, the teams who want to achieve an effective teamwork should start with sharing the meaning. Making constant efforts to create a culture that the team members will enable them to reach common understanding with related meanings is crucial.

Ethics Committee Approval: Authors declared that the research was conducted according to the principles of the World Medical Association Declaration of Helsinki "Ethical Principles for Medical Research Involving Human Subjects", (amended in October 2013).

Informed Consent: Verbal informed consent was obtained from health professionals who participated in this study.

Peer-review: Externally peer-reviewed.

Author contributions: Concept - F.O.; Design - F.O., G.A., F.A.; Supervision - F.O.; Resource - F.O., G.A., F.A.; Data Collection and/or Processing - F.O., G.A., F.A.; Analysis and/or Interpretation - F.O., G.A., F.A.; Literature Search - F.O., G.A., F.A.; Writing - F.O., G.A.; Critical Reviews - F.O., G.A., F.A.

Conflict of Interest: The authors have no conflicts of interest to declare.

Financial Disclosure: The authors declared that this study has received no financial support.

\section{REFERENCES}

I. Stuart GW. Integrating care delivery. In Stuart GW, Laraia MT, editors. Principles and Practice of Psychiatric Nursing. I0th ed. St Louis: Elsevier Mosby Inc. 2013. p. 644.

2. Knox GE $\delta$ Simpson KR. Teamwork: the fundamental building block of high-reliability organizations and patient safety. Youngberg BJ, Hatlie MJ editors. Patient Safety Handbook. Boston: Jones and Bartlett; 2004. p.379-4l5.

3. Liberman RP, Hilty DM, Drake RE, Tsang HW. Requirements for multidisciplinary teamwork in psychiatric rehabilitation. Psychiatr Serv 200।; 52(I0): |33|-42. [CrossRef]

4. Di Palma C. Power at Work: Navigating Hierarchies, Teamwork and Webs. J Med Humanit 2004; 25(4): 29I-308. [CrossRef]

5. Özdemir U. The evaluation of psychiatric care team's own knowledge about "team work" and the psychiatric treatment institutions. J Cris 1999; 7(2): 17-24. 
6. Stark S, Stronach I, Warne T. Teamwork in mental health: rhetoric and reality. JPMHN 2002; 9: 4II-8. [CrossRef]

7. Nemeth CP. The Context for improving healthcare team communication. In Improving Healthcare Team Communication: Building on Lessons from Aviation and Aerospace. Burlington: Ashgate Publishing Company; 2008. p.I-7, 245-50. [CrossRef]

8. Maddock A. Consensus or contention: an exploration of multidisciplinary team functioning in an Irish mental health context. Eur $\mathrm{J}$ Social Work 2015; 18(2): 246-61. [CrossRef]

9. Kerry MJ, Schmutz JB, Eppich WJ. Speaking up in defence of teamwork training towards patient safety: a response. Med Edu 2017; 51 : 560-2. [CrossRef]

10. Onyett S, Campling J. Teamworking in Mental Health. Basingstoke: Palgrave Macmillan Ltd. 2002.

II. Seebohm P, Secker J. Increasing the vocational focus of the community mental health team. J Int Care 2003; 17(3): 28I-91. [CrossRef]

12. Fleury MJ, Grenier G, Barnvita JM, Chiocchio F. Variables associated with work performance in multidisciplinary mental health teams. SAGE Open Med 2017; 5: I-12. [CrossRef]

13. Xyrichis A, Ream E. Teamwork: a concept analysis. J Adv Nurs 2008; 6I(2): 232-4l. [CrossRef]

14. Norman IJ, Peck E. Working together in adult community mental health services: An inter-professional dialogue. J Mental Health 1999; 8(3): 217-30. [CrossRef]

15. Hall P. Interprofessional teamwork: professional cultures as barriers. J Interprof Care 2005; 19(suppl I): 188-96. [CrossRef]

16. Fleury MJ, Grenier G, Barnvita JM, Chiocchio F. Associated nad Mediating Variables Related to Job staisfaction among Professional from Mental Health Teams. Psychiatry Q 2018; 89: 399-4I3. [CrossRef]

17. Körner M, Lippenberger C, Becker S, Reichler L, Müller C, Zimmermann $L$, et al. Knowledge integration, teamwork and performance in health care. J Health Organ Manag 20I6; 30(2): 227-43. [CrossRef]

18. Millward LJ, Jeffries $N$. The team survey: a tool for health care team development. J Adva Nurs 200I; 35(2): 276-87. [CrossRef]

19. Lo L. Teamwork and communication in healthcare a literature review. Canadian Patient Safety Institute, 20ll. Retrieved from: www. patientsafetyinstitute.ca/.../teamwork.com.

20. Hsieh HF, Shannon SE. Three approaches to qualitative content analysis. Qual Health Res 2005; 15: 1277-88. [CrossRef]
21. Blegen MA, Goode CJ, Park SH, Vaughn T, Spetz J. Baccalaureate education in nursing and patient outcomes. J Nurs Adm 2013; 43(2): 89-94. [CrossRef]

22. Kelly J. An overwiev of conflict. Dimens Crit Care Nurs 2006; 25(I): 22-8. [CrossRef]

23. Heimer A. Coflict resolution. RN Journal of Nursing, 2018. Available from: http://rn-journal.com/ journal of-nursing/conflict-resolution. Retrieved on 02.06 .2018

24. Shaw JD, Zhu J, Duffy MK, Scott KL, Shih HA d Susanto E. A contingency model of conflict and team effectiveness. J Appl Psychol 20II; 96(2): 391-400. [CrossRef]

25. JonesA. Multidisciplinary team working: collaboration and conflict. Int J Ment Health Nurs 2006; 15(I): 19-28. [CrossRef]

26. Leonard M, Frankel AS. Role of Effective Teamwork and Communication in Delivering Safe, High-Quality Care. Mt Sinai J Med 20II; 78(6): 820-6. [CrossRef]

27. McCaffrey A, Hayes RM, Cassell A, Miller-Reyes S, Donaldson A, Ferrel $C$. The effect of educational programme on attitudes of nurses and medical residents towards the benefits of positive communication and collaboration. J Adv Nurs 2012; 68(2): 293-30I. [CrossRef]

28. Singh SP. Running an effective community mental health team. Advances in Psychiatric Treatment 2000; 6: 4|4-22. [CrossRef]

29. Leggat SG. Effective healthcare teams require effective team members: defining teamwork competencies. BMC Health Services Research 2007; 7: 17. [CrossRef]

30. Nolan E, Hewison A. Teamwork in primary care mental health: a policy analysis. Journal of Nursing Management 2008; 16: 649-61. [CrossRef]

31. Baker DP, Day R, Salas E. Teamwork as an essential component of high-reliability organizations. Health Serv Res 2006; 4I(4-2): 1576-98. [CrossRef]

32. Simpson A. The impact of team processes on psychiatric case management. J Adv Nurs 2007; 60(4): 409-18. [CrossRef]

33. Holloway I. Qualitative research in Health care. Open University Press. 2005.

34. Sandelowsky M. Whatever happened to qualitative description? Res Nurs Health 2000; 23(4): 334-40. [CrossRef]

35. Wake-Dyster W. Designing teams that work. Australian Health Review 200l; 24(4): 34-4I. [CrossRef] 